\title{
A Matemática para os anos iniciais na BNCC e reflexões sobre a prática docente
}

\author{
Eliane Maria Vani Ortega ${ }^{1}$ \\ Universidade Estadual Paulista "Júlio de Mesquita Filho" - Unesp
}

\begin{abstract}
RESUMO
O presente artigo aborda os principais aspectos da Base Nacional Comum Curricular (BNCC) no que diz respeito à Matemática para os anos iniciais do Ensino Fundamental. Consideramos o processo de elaboração da BNCC desde sua origem e o contexto de aprovação marcado por interesses de diferentes grupos numa conjuntura política também marcada pela complexidade e disputas de diferentes ordens. Trata-se de análise documental e discussão das implicações da organização da BNCC para a prática dos professores que ensinam Matemática nos anos iniciais. São utilizados autores do campo da Educação e da Educação Matemática que tratam das questões curriculares e da prática docente. A BNCC, para o campo da Matemática nos anos iniciais, apresenta quadros divididos em cinco unidades temáticas (Números, Álgebra, Geometria, Grandezas e Medidas e Probabilidade e Estatística), objetos de conhecimento e habilidades. Do $1^{\circ}$ ao $5^{\circ}$ ano, são apresentadas 126 habilidades listadas por meio de códigos alfanuméricos. A partir da identificação das características da BNCC, destacamos reflexões necessárias para a prática docente nos anos iniciais. Além de atender tantas demandas da escola, dos alunos, de administrar seu desenvolvimento profissional, de sobreviver com salários baixos, condições de trabalho longes do ideal, temos receio de que cada uma dessas habilidades se torne apenas um item de uma listagem a mais para ser cobrada como responsabilidade desse professor e como algo fragmentado, sem a visão do todo que compõem a Matemática a ser desenvolvida na escola. A prática docente, para ser caracterizada como prática efetivamente pedagógica, envolve múltiplos aspectos e se os professores não forem envolvidos em tarefas de estudo, reflexão, discussão sobre as características da BNCC incorporadas pelo currículo do seu estado ou município, consideramos que pode haver implicações de caráter tecnicista, fragmentado, dificultando o exercício de uma prática reflexiva que deveria envolver não apenas cada unidade temática proposta na BNCC, mas uma melhor compreensão de tais unidades articuladas entre si e da Matemática como um todo.
\end{abstract}

Palavras-chave: Matemática na BNCC; Anos Iniciais; Prática docente.

${ }^{1}$ Doutora em Educação pela Faculdade de Educação da USP (FEUSP). Professora do Programa de PósGraduação em Educação da Universidade Júlio de Mesquita Filho/Unesp. Professora do Departamento de Educação da Faculdade de Ciências e Tecnologia da Unesp-FCT, Presidente Prudente, São Paulo, Brasil. Endereço para correspondência: Rua Martins Francisco nº 560-A, Jardim Tênis Clube, Regente Feijó-SP, CEP 19570-000. ORCID: http://orcid.org/0000- 0002-9962-8513. E-mail: vani.ortega@unesp.br 


\title{
Mathematics for the early years at BNCC and reflections about the teaching practice
}

\begin{abstract}
This paper addresses the main aspects of the National Common Curricular Base (BNCC) with regard to mathematics for the early years of elementary school. We consider the process of preparing the BNCC since its inception and the context of approval marked by the interests of different groups in a political context also marked by the complexity and disputes of different orders. It involves documentary analysis and discussion of the implications of the BNCC organization for the practice of teachers who teach mathematics in the early years. Authors from the field of Education and Mathematical Education who deal with curricular issues and teaching practice are used. The BNCC, for the field of Mathematics in the early years, presents tables divided into five thematic units (Numbers, Algebra, Geometry, Quantities and Measurements and Probability and Statistics), objects of knowledge and skills. From the 1st to the 5th year, 126 skills are presented, listed through alphanumeric codes. From the identification of the characteristics of the BNCC, we highlight reflections necessary for teaching practice in the early years. In addition to meeting so many demands from the school, from the students, from managing their professional development, from surviving on low wages, working conditions that are far from ideal, we are afraid that each of these skills will become just one item on one more listing for be charged as the responsibility of that teacher and as something fragmented, without the vision of the whole that make up Mathematics to be developed at school. Teaching practice, to be characterized as effectively pedagogical practice, involves multiple aspects and if teachers are not involved in study, reflection, discussion about the characteristics of BNCC incorporated into the curriculum of their state or municipality, we consider that there may be implications of technicist character, fragmented, making it difficult to exercise a reflexive practice that should involve not only each thematic unit proposed in the BNCC, but a better understanding of such articulated units and of Mathematics as a whole.
\end{abstract}

Keywords: Mathematics at BNCC; Early Years; Teaching practice.

\section{Matemáticas para los primeros años en BNCC y reflexiones sobre la práctica docente}

\begin{abstract}
RESUMEN
Este artículo aborda los principales aspectos de la Base Curricular Común Nacional (BNCC) con respecto a las matemáticas para los primeros años de la escuela primaria. Consideramos el proceso de elaboración del BNCC desde sus inicios y el contexto de aprobación marcado por los intereses de diferentes grupos en un contexto político también marcado por la complejidad y disputas de diferentes órdenes. Implica el análisis documental y la discusión de las implicaciones de la organización BNCC para la práctica de los profesores que enseñan matemáticas en los primeros años. Se utilizan autores del ámbito de la Educación y la Educación Matemática que abordan cuestiones curriculares y prácticas docentes. El BNCC, para el campo de las Matemáticas en los primeros años, presenta tablas divididas en cinco unidades temáticas (Números, Álgebra, Geometría, Cantidades y Medidas y Probabilidad y Estadística), objetos de conocimiento y habilidades. Del $1^{\circ}$ al $5^{\circ}$ curso se presentan 126 competencias, enumeradas mediante códigos alfanuméricos. A partir de la identificación de las características del BNCC destacamos reflexiones necesarias para la práctica docente en los primeros años. Además de satisfacer tantas demandas de la escuela, de los estudiantes, de gestionar su desarrollo profesional, de sobrevivir con salarios bajos, condiciones de trabajo lejos de las ideales, tememos que cada una de estas habilidades se convierta en un solo elemento de uno. más listado por cobrar como responsabilidad de ese docente y como algo fragmentado, sin la visión de conjunto que conforman las Matemáticas a desarrollar en la escuela. La práctica docente, al caracterizarse como práctica efectivamente pedagógica, involucra múltiples aspectos y si los docentes no se involucran en el estudio, reflexión, discusión sobre las características del BNCC incorporadas al currículo de su estado o municipio, consideramos que puede
\end{abstract}

Revista de Educação Matemática (REMat), São Paulo (SP), v. 19, n. 01, p. 01-23, e022001, 2022, eISSN: 2526-9062 DOI: $10.37001 /$ remat25269062v19id549

Sociedade Brasileira de Educação Matemática - Regional São Paulo (SBEM-SP) 
haber implicaciones de tecnicismo carácter, fragmentado, dificultando el ejercicio de una práctica reflexiva que debe involucrar no solo a cada unidad temática propuesta en el BNCC, sino a una mejor comprensión de dichas unidades articuladas y de la Matemática en su conjunto.

Palabras clave: Matemáticas en BNCC; Primeros años; Práctica docente.

\section{INTRODUÇÃO}

O desenvolvimento profissional do professor de educação básica está articulado às políticas e práticas de formação, que envolvem, entre outras variáveis, propostas e alterações curriculares. É importante compreender que o professor, no contexto de sua prática docente, sob diferentes aspectos, interage com propostas formuladas em documentos oficiais e tais documentos, ao longo do tempo vão sofrendo modificações.

No Brasil, em dezembro de 2017 foi aprovado o documento intitulado "Base Nacional Comum Curricular" (BNCC) (BRASIL, 2017). A partir deste documento, os estados e municípios vêm fazendo adequações curriculares, considerando o que está na BNCC e levando em conta suas especificidades locais.

Desde o início da elaboração da BNCC temos tido acesso a estudos sobre as características do processo de sua elaboração e da constituição do documento em suas diferentes versões. Entre embates de ordem técnica e política, principalmente nas duas primeiras versões, a terceira versão foi elaborada no Governo de Michel Temer, após o golpe parlamentar que resultou no Impeachment da Presidente Dilma Roussef. Tal versão foi encaminhada ao Conselho Nacional de Educação e após algumas alterações, a BNCC foi aprovada numa conjuntura política complexa, em dezembro de 2017, ainda sem a conclusão da parte relacionada ao Ensino Médio, que foi incorporada no ano de 2018.

Com a aprovação da BNCC em 2017, como pesquisadores na área de formação dos professores que ensinam Matemática nos anos iniciais do ensino fundamental e formadores de pedagogos na área de Matemática nesse nível de ensino, nos sentimos provocados a compreender melhor as características da BNCC no campo da Matemática proposta para os anos iniciais e propor reflexões que envolvem a prática do professor que atua nesse nível de ensino.

\footnotetext{
Revista de Educação Matemática (REMat), São Paulo (SP), v. 19, n. 01, p. 01-23, e022001, 2022, eISSN: $2526-9062$ DOI: $10.37001 /$ remat25269062v19id549

Sociedade Brasileira de Educação Matemática - Regional São Paulo (SBEM-SP)
} 
Dada a importância do tema e em razão dos poucos estudos feitos no campo da Matemática dos anos iniciais na BNCC, investigamos como a Matemática está organizada nesse documento. Trata-se de uma tarefa urgente analisar e refletir como um documento normativo, obrigatório, como a $\mathrm{BNCC}$, organiza o campo da Matemática.

Consideramos este trabalho importante, na medida que estados e municípios se organizaram ou ainda estão no processo de se organizar para elaboração do currículo a partir da BNCC. Nesse processo de organização para construção do currículo, é fundamental que tenhamos estudos que auxiliem os envolvidos a refletirem sobre a BNCC, sobre o ensino de Matemática nos anos iniciais e aspectos que envolvem a prática do professor diante desse documento.

\section{REVISÃO DE LITERATURA}

De acordo com Goodson (2013, p. 21), a etimologia da palavra currículo deriva do latim scurrere, que significa correr, curso. A ideia presente no termo está relacionada a algo a ser seguido. Entretanto, o autor aponta que é conflituosa a tentativa de esclarecer o significado de currículo, pois envolve a luta constante relacionada aos objetivos do processo de escolarização. “ O currículo escrito não passa de um testemunho visível, público e sujeito a mudanças, uma lógica que se escolhe para, mediante sua retórica, legitimar uma escolarização, à medida que vão sendo operacionalizadas em estruturas e instituições".

No decorrer dos séculos XVI e XVII, ao atender as funções de organizar, unificar, ordenar, selecionar conteúdos a serem ensinados e aprendidos, o currículo se tornou "uma invenção decisiva do que hoje é a escolaridade e de como a entendemos" (SACRISTÁN, 2013, p.18). Temos assim uma escola organizada em classes, ano letivo, conteúdos diferentes para cada classe dependendo do tempo já estudado. Ao mesmo tempo, cria-se um controle externo. Não se pode ensinar qualquer coisa que se deseja e nem em qualquer tempo. O currículo se configura como regulador, interferindo nas ações das pessoas envolvidas e definindo os parâmetros para o sucesso da escola ou não.

Sacristán (2013) afirma que o conceito explícito de currículo no campo educacional surge de forma mais sistemática por volta de 1983 e a partir daí os trabalhos com o objetivo de uma conceituação mais aprofundada foram crescendo. Tal crescimento, segundo o autor, 
se justifica principalmente em razão da escolaridade organizada para a massa. O currículo se apresenta como um território marcado por controvérsias e conflitos, na medida em que seu caráter regulador atende diferentes interesses e de diferentes setores da sociedade.

Sacristán (2000) afirma que o currículo é uma práxis e não deve ser considerado como à margem do sistema educativo, como algo que envolveria uma realidade abstrata. Há uma prática que decorre da função social e cultural do sistema educativo, prática relacionada às diferentes ações envolvidas dentro do sistema educativo, prática que envolve diálogo entre agentes sociais, elementos técnicos, alunos e professores.

O currículo, para Young (2011), tem o papel educativo de definir os objetivos das escolas e deve estar fundamentado em engajamento, uma atitude que supere a dimensão instrumental das diretrizes específicas dirigidas às escolas e aos professores. O currículo como instrumento, em geral, permite aos governos defenderem que vão reformar currículos para resolver problemas sociais e econômicos. Tal concepção acentua o papel de executores das escolas e professores, daí a necessidade de um currículo fundamentado em engajamento.

Para Lopes e Macedo (2011, p. 19), a definição de currículo não é uma tarefa simples, pois envolve a disputas e sentidos atribuídos a uma definição são "sempre parciais e localizados historicamente". As autoras descrevem o currículo como uma prática discursiva e, por conseguinte, uma prática de poder. Defendem ainda um currículo instituinte, que possa desconstruir discursos, hegemonias.

Bishop (1999) defende que o currículo deve estar fundamentado na cultura. No caso da Matemática, na medida em que a compreende como um fenômeno multicultural, defende a proposição de um currículo sustentado pelas características de investigação.

Santos (2003, p.6), cita o currículo como "amplo campo de estudos e significativas proposições". Nesta perspectiva, abrange "as condições em que o conhecimento matemático é produzido, usado e ensinado" e destaca a importância do multiculturalismo.

Godoy (2011, p. 188) trata da articulação do currículo, da educação e da escola num processo de regulação da sociedade e dos indivíduos. É por intermédio do currículo que “o Estado educa e sanciona os conhecimentos que devem ser aprendidos pelos estudantes". Os 
conceitos e os processos de escolarização são "práticas sociais historicamente constituídas" e se articulam com a sociedade. Nessa articulação são produzidas relações de poder

A partir das definições de currículo descritas pelos diferentes autores do campo, compreendemos que se este é marcado por conflitos de diversas ordens, é compreensível a existência das reformas curriculares, sempre vinculadas ao contexto político, econômico e social.

As reformas curriculares de Matemática não se situam à margem das discussões do campo mais geral de estudos sobre currículo. Para Pires (2000), as mudanças curriculares, em geral são acompanhadas por crenças no aperfeiçoamento do ensino, mas no Brasil, as implantações envolvem um processo lento e complexo. As reformas do currículo de Matemática são marcadas pela linearidade, onde os conceitos são sugeridos numa determinada sequência em que é necessário aprender um para depois estudar o outro. Para a autora, tal abordagem não tem sido adequada para a aprendizagem dos conceitos matemáticos.

Pires (2000) sugere que os currículos devem ir além das listagens de conteúdos. Deve ser uma estratégia da ação educativa, articulada a um projeto mais amplo de Educação. A autora destaca o papel da escola e o conhecimento dos professores no processo de organização curricular. Defende ainda o trabalho com eixos temáticos e não conteúdos isolados. Os eixos temáticos auxiliam no estabelecimento de conexões internas da Matemática e conexões com outras áreas do conhecimento. A autora também destaca a Resolução de Problemas como metodologia, na medida em que o foco central na aprendizagem em Matemática é a construção de conhecimento, com atribuição de sentido ao que está sendo ensinado/aprendido.

No Brasil, dentre as reformas por que passou o ensino de Matemática, vamos destacar em nível nacional, antes da Base Nacional Comum Curricular (BNCC), a elaboração dos Parâmetros Curriculares Nacionais (PCN), publicado em 1997. Para Pires e Silva (2011), os PCN foram elaborados no contexto de aprovação da Lei Federal n ${ }^{\circ} 9394$ de 20/12/1996. O objetivo era que tivéssemos em todo o país, parâmetros curriculares que pudessem funcionar como subsídio para adaptações locais, considerando as diferenças regionais e especificidades das escolas. 
As principais proposições contidas nos PCN de Matemática segundo Pires e Silva (2011) estão descritas a seguir:

- Ênfase no papel da Matemática como instrumento de compreensão da realidade;

- Estímulo ao desenvolvimento da criatividade, curiosidade, atitude de investigação;

- Desenvolvimento da segurança para resolver problemas;

- Processo de seleção de conteúdos orientados pela relevância social e intelectual;

- Conteúdos descritos sob a forma de conceitos, procedimentos e atitudes;

- Construção do conhecimento matemático num processo de rede, de teia de relações, superando a abordagem linear;

- Conexões entre blocos de conteúdos dentro da própria Matemática e com outras áreas de conhecimento;

- Resolução de problemas como o ponto de partida do processo de ensino e aprendizagem de Matemática;

-Utilização da História da Matemática, Jogos, Tecnologias da Informação e comunicação.

Nos PCN (Brasil, 1997), a Matemática é considerada como componente importante para a construção da cidadania, deve estar ao alcance de todos e por isso deve estar diretamente relacionada à compreensão. Para efetivar tal compreensão, os alunos precisam fazer conexões, estabelecer relações e atribuir sentido ao que está estudando.

As relações dizem respeito a conteúdos que fazem parte do cotidiano das pessoas, como contar, medir, estimar, calcular a probabilidade de um fenômeno ocorrer ou não, investigar qual formato é mais adequado para um objeto e o melhor caminho para se locomover, entretanto, as relações devem ser provocadas também, diante de temáticas que não se aplicam diretamente à realidade dos indivíduos, mas auxiliam no processo de estruturação do raciocínio lógico dedutivo, quando se abordam conceitos considerados mais abstratos.

\footnotetext{
Revista de Educação Matemática (REMat), São Paulo (SP), v. 19, n. 01, p. 01-23, e022001, 2022, eISSN: $2526-9062$ DOI: $10.37001 /$ remat25269062v19id549

Sociedade Brasileira de Educação Matemática - Regional São Paulo (SBEM-SP)
} 
Para Gatti, Barreto e André (2011), nas reformas pós anos 90, os esforços na área educacional tiveram como horizonte desafios propostos por demandas de ordem social, econômica e cultural e com forte preocupação com o contexto dos direitos humanos. Nesse contexto, a Educação é um direito humano e daí políticas de ampliação do acesso à escolarização. Nesse processo de ampliação da escolarização, o currículo exerce um papel chave.

Para as autoras, as mudanças curriculares pós anos 90 tem apresentado uma “orientação acentuadamente diretiva" (p.44). Nos documentos oficiais se procura detalhar o que ensinar, como, quando e como avaliar. A autonomia do professor fica assim, restringida. "Esse modo de regulação, chamado econômico-burocrático por Hargreaves (2003), tem sido feito, por vezes, de forma conflituosa, provocado enfrentamentos com sindicatos e associações docentes.” (GATTI; BARRETO; ANDRÉ, 2011, p. 44)

Predomina nas perspectivas formativas das últimas décadas (entre 90 até 2010), o discurso da competência, que as autoras reconhecem a importância, mas descrevem a preocupação com a competência subordinada às demandas socioeconômicas, descontextualizada das dimensões social e relacional, o que aproximaria melhor das necessidades dos indivíduos. Entre os anos de 2003 e 2010, as referências nacionais relacionadas ao currículo foram mantidas, com ampliação da preocupação de superar as desigualdades e injustiças. Nesse contexto, ganham destaque o direito à diferença, à participação, inclusão e com aspectos democráticos. (GATTI; BARRETO; ANDRÉ, 2011)

Neste contexto de adequações curriculares, e como cumprimento de artigos da Constituição de 1988, da LDB 9394/96 e das metas do Plano Nacional de Educação (PNE) de 2014, temos o início do processo de elaboração da Base Nacional Comum Curricular. De acordo com Moreno (2016, p. 10), tal processo foi organizado pelo Ministério da Educação, União Nacional dos Dirigentes Municipais de Educação (UNDIME), do Conselho Nacional de Secretários de Educação (CONSED) e Conferência Nacional dos Trabalhadores da Educação (CNTE). Entretanto, para o autor, é importante relatar que além dos envolvidos já citados com o objetivo de cumprir as metas do PNE 2014, a criação do "Movimento pela Base Nacional Comum da Educação em abril de 2013" interferiu no processo de elaboração da BNCC. Tal movimento foi "formado por fundações e institutos mantidos pela iniciativa 
privada”. Houve momentos em que foi aberta consulta pública para análise das versões preliminares.

A primeira versão da BNCC, no ano de 2015, teve participação, ainda que reduzida, de pesquisadores da Educação Matemática. A segunda versão, um pouco mais aberta à participação desses pesquisadores, incluiu pareceristas críticos representando diferentes sociedades científicas. A partir do Impeachment, como confirmam Passos e Nacarato (2018), houve destituição da equipe elaboradora da segunda versão e a terceira versão foi concluída com especialistas convidados e representantes de grupos empresariais. Enviada ao Conselho Nacional de Educação, a terceira versão sofreu pequenas modificações e então foi aprovada em 22 de dezembro de 2017 por meio da Resolução CNE/CP n ${ }^{\circ}$ 2, que "Institui e orienta a implantação da Base Nacional Comum Curricular, a ser respeitada obrigatoriamente ao longo das etapas e respectivas modalidades no âmbito da Educação Básica.”

A partir da aprovação da BNCC, fizemos levantamento de dissertações e teses produzidas no período entre 2014 e 2020 para identificar as produções envolvendo a temática que nos interessa no presente artigo, mais especificamente a Matemática na BNCC nos anos iniciais.

Utilizamos duas bases de dados para busca de trabalhos que pudessem estar relacionados à temática de interesse do presente artigo: o Catálogo de Teses e Dissertações da Capes e a Biblioteca Digital Brasileira de Teses e Dissertações. Inicialmente, usamos os descritores "Matemática" AND "BNCC". Apareceram no Catálogo da Capes 87 trabalhos e na BDTD, 70. Consideramos mais adequado, a partir da consulta à diversidade dos trabalhos, e como vários deles estavam distantes do nosso foco de interesse, decidimos realizar a busca utilizando "Matemática" AND "BNCC" AND "Anos iniciais". A partir desses três descritores, no Catálogo da Capes encontramos 3 trabalhos, e na BDTD, 11.

Os três trabalhos encontrados no Catálogo da Capes estão descritos no quadro 1, que identifica o tipo de trabalho, se é mestrado, mestrado profissional ou doutorado, título, autor e orientador, ano da defesa e se tem como foco a temática do nosso artigo ou apenas tangencia a temática. 
Quadro 1- Levantamento de teses e dissertações do catálogo da Capes

\begin{tabular}{|c|c|c|c|c|}
\hline Tipo de trabalho & Título & Autor/Orientador & Ano & $\begin{array}{l}\text { Foco na } \\
\text { temática ou } \\
\text { tangencia a } \\
\text { temática }\end{array}$ \\
\hline Dissertação & $\begin{array}{lrr}\text { Early Algebra } & \text { na } \\
\text { perspectiva do } & \text { Livro } \\
\text { Didático } & & \\
\end{array}$ & $\begin{array}{l}\text { Daiane Venancio } \\
\text { Bitencoutrt/Vera } \\
\text { Lucia Merlini }\end{array}$ & 2018 & $\begin{array}{l}\text { Tangencia a } \\
\text { temática } \\
\text { (Pensamento } \\
\text { algébrico nos } \\
\text { livros didáticos, } \\
\text { cita a BNCC) }\end{array}$ \\
\hline $\begin{array}{l}\text { Dissertação/Mestrado } \\
\text { Profissional }\end{array}$ & $\begin{array}{llr}\text { Fração: Um } & \text { Novo } \\
\text { Número, um } & \text { Novo } \\
\text { Desafio- A introdução ao } \\
\text { ensino de frações nos anos } \\
\text { iniciais do } \\
\text { Fundamental }\end{array}$ & $\begin{array}{l}\text { Silvana Pires Fonseca } \\
\text { Mandarino/Neide da } \\
\text { Fonseca Parracho } \\
\text { Sant Anna }\end{array}$ & 2019 & $\begin{array}{l}\text { Tangencia a } \\
\text { temática } \\
\text { (produto } \\
\text { educacional } \\
\text { sobre frações } \\
\text { nos anos iniciais } \\
\text { do Ensino } \\
\text { Fundamental, } \\
\text { cita a BNCC) }\end{array}$ \\
\hline Dissertação & $\begin{array}{l}\text { O trilhar da construção de } \\
\text { um jogo pedagógico como } \\
\text { ferramenta para o ensino } \\
\text { de probabilidade nos anos } \\
\text { iniciais do ensino } \\
\text { fundamental }\end{array}$ & $\begin{array}{l}\text { Nilceia Datori } \\
\text { Barbosa/Ailton Paulo } \\
\text { de Oiveira Junior }\end{array}$ & 2019 & $\begin{array}{l}\text { Tangencia a } \\
\text { temática } \\
\text { (probabilidade } \\
\text { nos anos } \\
\text { iniciais, cita a } \\
\text { BNCC) }\end{array}$ \\
\hline
\end{tabular}

Fonte: levantamento organizado pela autora

Os três trabalhos referem-se a conteúdos específicos de Matemática, a saber: o tratamento da questão do pensamento algébrico nos livros didáticos, produto educacional voltado para o trabalho com frações nos anos iniciais e uso de jogo para o ensino de probabilidade nos anos iniciais. A partir da leitura dos resumos, identificamos preocupações específicas com o ensino dos conceitos centrais a que se propõem e a BNCC é citada como o documento normativo que deve ser considerado, mas o foco não é analisar a forma como os diferentes conceitos estão descritos nesse documento. Daí classificarmos em trabalhos que tangenciam a temática do nosso artigo.

Na BDTD, encontramos 11 trabalhos, mas apenas 7 (descritos no quadro 2) se encaixavam no objetivo da busca. 
Quadro 2 - Levantamento de teses e dissertações da BDTD

\begin{tabular}{|c|c|c|c|c|}
\hline $\begin{array}{l}\text { Tipo de } \\
\text { trabalho }\end{array}$ & Título & Autor/Orientador & Ano & $\begin{array}{l}\text { Foco na temática ou } \\
\text { tangencia a } \\
\text { temática }\end{array}$ \\
\hline Dissertação & $\begin{array}{l}\text { Matemática financeira: } \\
\text { proposta utilizando a BNCC }\end{array}$ & \begin{tabular}{|l} 
REGONHA, \\
Mariane Rodrigues/ \\
Gadotti, Marta \\
Cilene [UNESP] \\
\end{tabular} & 2019 & $\begin{array}{l}\text { Tangencia a temática } \\
\text { (ensino de } \\
\text { Matemática } \\
\text { Financeira para } \\
\text { professores dos anos } \\
\text { iniciais). Cita a } \\
\text { BNCC. }\end{array}$ \\
\hline Tese & $\begin{array}{l}\text { Escala apresentada em gráficos: } \\
\text { conhecimentos matemáticos para o } \\
\text { ensino dos anos iniciais do ensino } \\
\text { fundamental (crianças e Eja) }\end{array}$ & \begin{tabular}{|l} 
ALBUQUERQUE, \\
Milka Rossana \\
Guerra Cavalcanti \\
de/ \\
GUIMARÃES, Gilda \\
Lisbôa \\
\end{tabular} & 2018 & $\begin{array}{l}\text { Tangencia a temática } \\
\text { (trabalha com escalas } \\
\text { em gráficos nos anos } \\
\text { iniciais). Cita a } \\
\text { BNCC. }\end{array}$ \\
\hline Dissertação & $\begin{array}{l}\text { O desenvolvimento do pensamento } \\
\text { geométrico: uma proposta de } \\
\text { recurso didático por meio da } \mathrm{HQ}\end{array}$ & \begin{tabular}{|l} 
SOUZA, Patrícia \\
Priscilla Ferraz da \\
Costa/ \\
PIROLA, Nelson \\
Antônio \\
\end{tabular} & 2018 & $\begin{array}{l}\text { Tangencia a temática } \\
\text { (ensino de Geometria } \\
\text { no } 5^{\circ} \text { ano, proposta } \\
\text { de recurso didático). } \\
\text { Cita a BNCC. }\end{array}$ \\
\hline Dissertação & $\begin{array}{l}\text { As mudanças geradas pela Base } \\
\text { Nacional Comum Curricular } \\
\text { (BNCC) em uma coleção de livros } \\
\text { didáticos para o ciclo de } \\
\text { alfabetização na abordagem do } \\
\text { pensamento algébrico }\end{array}$ & \begin{tabular}{|l} 
FAVERO, Débora \\
Cristina Borba \\
Pereira/ \\
MANRIQUE, Ana \\
Lucia
\end{tabular} & 2020 & $\begin{array}{l}\text { Tangencia a temática } \\
\text { (análise de livros } \\
\text { didáticos quanto ao } \\
\text { pensamento } \\
\text { algébrico a partir das } \\
\text { mudanças contidas } \\
\text { na BNCC). }\end{array}$ \\
\hline
\end{tabular}




\begin{tabular}{|c|c|c|c|c|}
\hline Dissertação & $\begin{array}{l}\text { Jogar, aprender e ensinar: } \\
\text { ressignificação da matemática por } \\
\text { estudantes de pedagogia }\end{array}$ & $\begin{array}{l}\text { SILVA, Gileade } \\
\text { Cardoso/ } \\
\text { SÁ, Antônio Villar } \\
\text { Marques de }\end{array}$ & 2019 & $\begin{array}{l}\text { Tangencia a temática } \\
\text { (jogos no processo de } \\
\text { formação } \\
\text { pedagogo do } \\
\text { aprender } \\
\text { Matemática) Cita a } \\
\text { BNCC. }\end{array}$ \\
\hline Dissertação & $\begin{array}{l}\text { Contribuições da compreensão } \\
\text { relacional e da instrumental em } \\
\text { atividades envolvendo grandezas e } \\
\text { medidas no ensino fundamental }\end{array}$ & $\begin{array}{l}\text { JULY, Fabielli Vieira } \\
\text { de/ LEIVAS, José } \\
\text { Carlos Pinto }\end{array}$ & 2020 & $\begin{array}{l}\text { Tangencia a temática } \\
\text { (foco em grandezas e } \\
\text { medidas no ensino } \\
\text { fundamental) Cita a } \\
\text { BNCC. }\end{array}$ \\
\hline Dissertação & $\begin{array}{l}\text { Pensamento algébrico no currículo } \\
\text { do ciclo de alfabetização:estudo } \\
\text { comparativo de duas propostas }\end{array}$ & $\begin{array}{l}\text { LIMA, José Roberto } \\
\text { de Campos / } \\
\text { BIANCHINI, } \\
\text { Barbara Lutaif } \\
\end{array}$ & 2018 & $\begin{array}{l}\text { Tangencia a temática } \\
\text { (pensamento } \\
\text { algébrico no } \\
\text { currículo prescrito do } \\
\text { ciclo de } \\
\text { alfabetização, } \\
\text { considerando } \\
\text { BNCC, e Orientações } \\
\text { Curriculares de } \\
\text { Matemática para os } \\
\text { Anos Iniciais } \\
\text { (OCMAI). }\end{array}$ \\
\hline
\end{tabular}

Fonte: Levantamento organizado pela autora

Os sete trabalhos encontrados na BDTD tratam de questões voltadas também para conteúdos específicos: matemática financeira para professores dos anos iniciais, escalas utilizadas em gráficos nos anos iniciais, pensamento algébrico nos anos iniciais, jogos matemáticos na formação de pedagogos e grandezas e medidas nos anos iniciais. Em todos esses trabalhos a BNCC é considerada como documento de referência e o foco não é analisar como este documento se estrutura, mas se os conceitos a serem desenvolvidos estão de acordo com o que já está determinado no documento oficial.

Diante do contexto que envolve estudos sobre o currículo, da aprovação da BNCC e dos trabalhos produzidos na área, consideramos de fundamental importância analisar a estrutura da BNCC na área de Matemática, em especial nos anos iniciais do ensino 
fundamental. Discutimos, a partir de tal estrutura, aspectos que podem ter implicações para a prática do professor polivalente que ensina Matemática nos anos iniciais.

Em relação à prática docente, Franco (2016, p. 536) defende que esta seja construída de forma relacionada ao fazer pedagógico e para tal, precisa considerar "a mediação do humano e não a submissão do humano a um artefato técnico previamente construído." A prática docente deve ser relacional e são múltiplas as determinações que interferem.

\footnotetext{
Quando se afirma que as práticas pedagógicas são práticas que se realizam para organizar/potencializar/interpretar as intencionalidades de um projeto educativo, argumenta-se a favor de outra epistemologia da Pedagogia: uma epistemologia crítico-emancipatória, que considera a Pedagogia uma prática social conduzida por um pensamento reflexivo sobre o que ocorre nas práticas educativas, bem como por um pensamento crítico do que pode ser a prática educativa. (FRANCO, 2016, p. 537)
}

Franco (2016) afirma que a prática docente não envolve apenas as questões didáticas, mas questões relacionadas às perspectivas e expectativas da profissão docente e as características do espaço em que ocorre o processo de ensino e aprendizagem. Ainda, é fundamental que o professor reflita constantemente e criticamente sobre sua prática. É preciso ter consciência das intenções que sustentam tal prática.

\section{METODOLOGIA}

Trata-se de investigação de natureza qualitativa de abordagem descritiva-analítica por meio de análise documental. O documento analisado neste trabalho é a versão aprovada em dezembro de 2017 da BNCC contendo a parte de Matemática para os anos iniciais.

A análise documental, de acordo com Lüdke e André (1986), se faz necessária quando o pesquisador, diante de uma questão de interesse, se depara com um documento que pode responder aos seus questionamentos. A vantagem do estudo documental é o fato do documento ser uma fonte estável, que persiste no tempo.

Para Cellard (2008), “o documento permite acrescentar a dimensão do tempo à compreensão social” (p. 295). O autor defende a necessidade de considerar o contexto de produção do documento a ser analisado, verificar a autenticidade e confiabilidade do documento, a natureza do texto, os conceitos-chave e a lógica interna do texto.

\footnotetext{
Revista de Educação Matemática (REMat), São Paulo (SP), v. 19, n. 01, p. 01-23, e022001, 2022, eISSN: 2526-9062 DOI: $10.37001 /$ remat25269062v19id549

Sociedade Brasileira de Educação Matemática - Regional São Paulo (SBEM-SP)
} 
A partir da análise da BNCC no que tange ao conhecimento matemático nos anos iniciais do ensino fundamental, apresentamos resultados tendo como suporte estudos do campo da Educação e da Educação Matemática, principalmente sobre currículo, currículo de matemática e relações entre currículo e prática docente.

\section{RESULTADOS}

No documento aprovado, a BNCC é descrita como referência nacional obrigatória para a educação escolar, que inclui as instituições que irão elaborar ou adequar seus currículos e propostas pedagógicas. Defende-se uma educação integral, definida como aquela que deve promover o acolhimento e o desenvolvimento pleno dos aprendizes, com amplo respeito às diferenças, numa perspectiva de combate à discriminação e preconceito. Trata-se de um documento normativo, que define 10 competências gerais e patamares comuns de aprendizagens a todos os alunos. Competência é definida no documento como "mobilização de conhecimentos (conceitos e procedimentos), habilidades (práticas, cognitivas e socioemocionais), atitudes e valores para resolver demandas complexas da vida cotidiana, do pleno exercício da cidadania e do mundo do trabalho.” (BRASIL, 2017, p.8)

$\mathrm{Na} \mathrm{BNCC}$, nos anos iniciais do ensino fundamental, há a preocupação com o desenvolvimento de atividades lúdicas, articuladas ao que as crianças vivenciaram na Educação Infantil, mas com progressiva sistematização das experiências vivenciadas. (Brasil, 2017)

A área de Matemática é considerada fundamental no documento da BNCC tanto em razão das aplicações na sociedade contemporânea como pela possibilidade de interferir na formação de cidadãos críticos. A Matemática é apresentada como ciência que estuda fenômenos determinísticos e aleatórios e é uma ciência hipotético-dedutiva. Consideramos que apesar de no âmbito da Educação Matemática essa forma de apresentar a Matemática não represente algo novo, questionamos se para os professores polivalentes há compreensão efetiva do significado desses aspectos destacados. Ainda, se há espaço e tempo para reflexão aprofundada do significado que envolve a dimensão determinística e aleatória do conhecimento matemático. É de fundamental importância que os professores que ensinam Matemática nos anos iniciais tenham clareza sobre tais aspectos, pois o processo de 
organizar o ensino e aprendizagem sofre influência da visão que os professores têm sobre a Matemática.

No Ensino Fundamental, a área de Matemática é apresentada por meio da articulação de seus diversos campos - Aritmética, Álgebra, Geometria, Estatística e Probabilidade, e tem como objetivo

garantir que os alunos relacionem observações empíricas do mundo real a representações (tabelas, figuras e esquemas) e associem essas representações a uma atividade matemática (conceitos e propriedades), fazendo induções e conjecturas. Assim, espera-se que eles desenvolvam a capacidade de identificar oportunidades de utilização da Matemática para resolver problemas, aplicando conceitos, procedimentos e resultados para obter soluções e interpretá-las segundo os contextos das situações. A dedução de algumas propriedades e a verificação de conjecturas, a partir de outras, podem ser estimuladas, sobretudo ao final do ensino fundamental. (BRASIL, 2017, p. 265)

Nos anos iniciais há preocupação com o letramento matemático, entendido como processo que envolve competências e habilidades relacionadas à representação, comunicação e argumentação, que favorecem "o estabelecimento de conjecturas, a formulação e a resolução de problemas em uma variedade de contextos, utilizando conceitos, procedimentos, fatos e ferramentas matemáticas. (BRASIL, 2017, p. 264).

A preocupação com o letramento matemático não é marca de ineditismo da BNCC. Já havia uma preocupação com a alfabetização matemática na perspectiva do letramento no campo da Educação Matemática. Um exemplo é o Programa Pacto Nacional pela Alfabetização na Idade Certa (PNAIC) que durante o governo da então Presidente Dilma Roussef, foi desenvolvido no Brasil com a preocupação de garantir a alfabetização tanto relacionada à língua materna, como à matemática e científica, nos três primeiros anos do ensino fundamental. Passos e Nacarato (2018) destacam a importância do PNAIC, que defendia o letramento matemático como prática social, e investiu na formação continuada dos professores alfabetizadores, a partir de amplo grupo de pesquisadores e professores de várias regiões do Brasil. No caso da BNCC, o letramento matemático é definido a partir da Matriz de Avaliação do PISA 2012 e volta-se para as habilidades, tendo um enfoque mais individual voltado para o estudante.

Em relação ao estabelecimento de conjecturas, formulação de hipóteses, também questões já apontadas em outros documentos curriculares ou resultados de estudo na área, 
há praticamente um consenso sobre a importância, mas questionamos que se não houver uma sólida formação dos professores polivalentes relacionada aos conceitos matemáticos a serem ensinados nos anos iniciais, como articular esse processo? Curi (1995) afirma que há lacunas na formação inicial dos pedagogos em Matemática. É importante destacar que o fato de estar registrado pontos importantes na $\mathrm{BNCC}$ de Matemática, não implica na apropriação direta e imediata de princípios enunciados.

O documento da BNCC destaca a Resolução de Problemas e a Modelagem Matemática como objetos e estratégias para a aprendizagem que deve voltar-se para o desenvolvimento de competências. Além das competências gerais da BNCC, em Matemática são enunciadas competências específicas, que resumimos a seguir:

reconhecer que a Matemática é uma ciência construída pelo homem inserido em seu contexto histórico para responder às demandas de seu tempo;

- desenvolver o raciocínio lógico por meio da atitude de investigação para compreensão e intervenção na realidade;

- compreender as relações internas entre os conceitos dos diferentes campos matemáticos e as relações com outras áreas do conhecimento;

- Realizar observações de aspectos quantitativos e qualitativos decorrentes da prática social e cultural e ser capaz de comunicar resultados, analisar e criticar;

- Utilizar ferramentas matemáticas, incluindo tecnologias digitais com objetivo de resolver problemas;

- Desenvolver projetos relacionados a "questões de urgência social, com base em princípios éticos, democráticos, sustentáveis e solidários, valorizando a diversidade de opiniões de indivíduos e de grupos sociais, sem preconceitos de qualquer natureza.” (p.267)

Interagir com os pares na busca de soluções e desenvolver perseverança na busca de resultados.

As competências específicas são importantes, também aparecem em documentos como os Parâmetros Curriculares Nacionais (1997). Ocorre que, para atingir tais competências, é fundamental que os professores que ensinam Matemática nos anos iniciais precisam compreender cada item dessas competências a partir de um processo de reflexão sobre a Matemática, sua natureza, sobre a relação Matemática escolar e sociedade entre outras questões. Esse profissional, não trabalha apenas com Matemática. E as outras 
disciplinas? Como articular o estudo aprofundado das questões necessárias sem descuidar do estudo das demais áreas?

São destacadas ainda na BNCC algumas ideias fundamentais a serem desenvolvidas no Ensino Fundamental: equivalência, ordem, proporcionalidade, interdependência, representação, variação e aproximação. Tais ideias são desenvolvidas por meio de cinco unidades temáticas: Números, Álgebra, Geometria, Grandezas e Medidas e Probabilidade e Estatística. Essas unidades compõem os blocos de conteúdos descritos nos PCN (Números e Operações, Grandezas e Medidas, Espaço e Forma e Tratamento da Informação), com nomenclatura diferente e no caso da álgebra, nos $\mathrm{PCN}$, não há um eixo explícito como na BNCC, embora esta estivesse integrada nos blocos dos conteúdos. As unidades temáticas são subdivididas em objetos do conhecimento e habilidades em cada ano dos anos iniciais do ensino fundamental.

Como professores que atuam na formação de pedagogos e participam constantemente de ações de formação continuada com professores dos anos iniciais, não consideramos que as ideias de equivalência, ordem, proporcionalidade, interdependência, representação, variação e aproximação são termos claros para os professores polivalentes. Consideramos necessário que seja organizado no processo de construção do currículo no âmbito municipal e estadual, estudo mais detalhado desses termos e significados para a prática docente dos professores que ensinam Matemática nos anos iniciais.

Em relação ao detalhamento dos conteúdos, na BNCC, há quadros organizados por ano contendo unidades temáticas, objetos de conhecimento e habilidades. No quadro 3, segue um recorte da unidade temática números do primeiro ano para exemplificar. 
Quadro 3 - Recorte da unidade temática números do primeiro ano- BNCC Matemática

\begin{tabular}{|c|c|c|}
\hline UNIDADES TEMÁTICAS & $\begin{array}{ll}\text { OBJETOS } & \text { DE } \\
\text { CONHECIMENTO } & \end{array}$ & HABILIDADES \\
\hline Números & $\begin{array}{l}\text { Contagem de rotina } \\
\text { Contagem ascendente } \\
\text { descendente } \\
\text { Reconhecimento de números no } \\
\text { contexto diário: indicação de } \\
\text { quantidades, indicação de ordem } \\
\text { ou indicação de código para a } \\
\text { organização de informações }\end{array}$ & $\begin{array}{l}\text { (EF01MA01) Utilizar números } \\
\text { naturais como indicador de } \\
\text { quantidade ou de ordem em diferentes } \\
\text { situações cotidianas e reconhecer } \\
\text { situações em que os números não } \\
\text { indicam contagem nem ordem, mas } \\
\text { código de identificação. }\end{array}$ \\
\hline
\end{tabular}

Fonte: BNCC de Matemática (Brasil, 2017, p. 280)

Para cada ano temos quadros que listam os objetos de conhecimento articulados às habilidades em cada unidade temática. Nos 5 anos temos um total de 126 habilidades listadas. Ao olhar atentamente para cada uma dessas 126 habilidades, indagamos se não corremos o risco de, na iminência de atender tantas demandas da escola, dos alunos, de administrar seu desenvolvimento profissional, de sobreviver com salários baixos, condições de trabalho longes do ideal, se cada uma dessas habilidades não aparecem apenas como uma listagem a mais para ser cobrada como responsabilidade desse professor e como algo fragmentado, sem a visão do todo que compõem todo o processo da Matemática a ser desenvolvida na escola.

Passos e Nacarato (2018, p. 120) afirmam que "a maioria dos educadores matemáticos rejeita a ideia de um currículo por competências e habilidades, tal como propõe a BNCC." Também destacam as lacunas conceituais que apresentam a maioria dos professores que ensinam Matemática nos anos iniciais e alertam para as consequências das ações de grupos empresariais mediando o processo de apropriação pelos professores da BNCC. Um exemplo são os "Planos de Aula. Nova Escola" que envolvem grupos de professores de Matemática que criam materiais online para uso dos professores, articulada à BNCC. Concordamos com as autoras que modelos prontos e padronizados de aula não atendem a necessidades de professores, que em geral, são pressionados a atender demandas 
que chegam às escolas sem tempo suficiente para discussão e reflexão e que são necessárias práticas reflexivas durante o desenvolvimento profissional dos professores, com foco na autonomia e compromisso ético diante da formação dos alunos.

\begin{abstract}
Os planos de aula apresentam o conteúdo, o roteiro, o controle de tempo para cada ação do professor, e indicam questões a serem feitas aos alunos e como o professor pode avaliar o desempenho deles. Propostas deste tipo estão na contramão do que entendemos por Matemática e seu ensino. A natureza do conhecimento matemático deve estar intrínseca ao trabalho do professor de modo que possibilite ao estudante fazer Matemática, que significa construí-la, produzi-la, por meio de resolução de problemas inteligentes ou desafiadores. (PASSOS e NACARATO, 2018, p. 126)
\end{abstract}

Consideramos preocupante e como retrocesso, propor ao professor coisas prontas, como se ele não tivesse condições de construir seu próprio repertório de trabalho. Ainda que muitos tenham dificuldades com a Matemática, não seria mais apropriado que tivéssemos formação continuada sobre a natureza da Matemática, sobre os conceitos, sobre como articular os princípios gerais propostos na BNCC e as habilidades elencadas? A forma que está organizada a BNCC de Matemática nos anos iniciais, em nossa visão, parece atender mais princípios tecnicistas do que declara nos princípios gerais. Morgado e Martins (2008) afirmam que as políticas educativas e curriculares têm realçado o papel do professor, já que é este que terá que contextualizar, adequar e enriquecer o currículo que é proposto pelos órgãos institucionais. A implementação de alterações curriculares "só faz sentido se provocar uma mudança das práticas docentes”. Se não houver mudança, há o risco de redução ao mero "cumprimento de uma determinação legal, numa lógica essencialmente tecnicista de desenvolvimento curricular". (p.14)

Mainardes (2006) destaca que os textos legais oficiais das políticas educacionais são resultantes de disputas e acordos, mas não podemos ignorar que estão sujeitos ao contexto no qual serão concretizados ou não. Professores e outros profissionais das escolas interferem no processo de interpretação e reinterpretação dos documentos oficiais advindos das políticas educacionais. Tal fato ocorre em razão das diferentes crenças desses profissionais, que influenciam o processo de implementação de políticas, incluindo as curriculares.

Segundo Lopes (2005), os textos oficiais ou não que circulam entre os professores e gestores na escola estão sujeitos às reinterpretações, negociações, legitimação de alguns aspectos em detrimento de outros. 
Em relação aos textos oficiais, como a BNCC, antes da apropriação das suas características pelos professores, entendemos que apenas teremos implicações positivas para a prática docente, se forem amplamente discutidos, questionados, durante a elaboração e no processo de implementação. Caso contrário, a prática docente pode ser reduzida a uma prática orientada para técnicas sem sentido e não uma prática efetivamente pedagógica, repleta de intencionalidade e reflexão crítica como defende Franco (2016).

\section{CONSIDERAÇÕES FINAIS}

Diante de um documento normativo em nível nacional, obrigatório, cabe o questionamento sobre a relação entre o que propõe tal documento e a prática do professor de matemática dos anos iniciais do ensino fundamental.

Considerando a prática docente como o movimento do professor que ensina Matemática nos anos iniciais quando planeja sua aula, quando seleciona atividades para utilizar com seus alunos, quando apresenta dúvidas e troca experiências com seus colegas, quando participa das discussões e estudos com a equipe de gestão escolar, entendemos que as características apresentadas neste texto sobre a configuração da BNCC de Matemática para os anos iniciais torna necessário um processo detalhado de estudo e reflexão que vai desde a forma de aprovação do documento até questões pontuais envolvendo diferentes conceitos matemáticos. É fundamental considerar a BNCC desde sua origem, o contexto de elaboração das diferentes versões bem como o contexto de aprovação marcado por interesses de diferentes grupos numa conjuntura política também marcada pela complexidade e disputas de diferentes ordens.

Quanto aos quadros contendo as unidades temáticas, os objetos de conhecimento e as habilidades, também defendemos que antes de qualquer construção do currículo no espaço escolar, é imprescindível que os professores tenham tempo de estudo, reflexão, discussão, levantamento de dúvidas, sobre a Matemática como um todo e não fragmentada em habilidades, sobre as ideias envolvidas e a compreensão com sentido dos conceitos a serem desenvolvidos em todos os anos do ensino fundamental. Sem esse processo será muito difícil atender aos princípios enunciados nas competências específicas enunciadas na própria BNCC.

Cumpre salientar que documentos oficiais, livros didáticos, materiais propostos seja por instituições públicas ou de caráter empresarial precisam fazer sentido para quem está 
inserido em sala de aula, exercendo a prática docente, ou seja, para os professores. Tais profissionais, por meio de suas práticas, têm condições de efetivar propostas mais voltadas para formação integral, crítica, humanizadora ou não. Daí a importância do processo de reflexão no espaço escolar para além de cumprir currículos prescritos e voltado para a compreensão das forças contraditórias presentes na elaboração de diferentes materiais curriculares e com consequências para a prática docente. Consideramos que tal processo de reflexão está intimamente relacionado à valorização e melhoria das condições de trabalho desses professores.

\section{REFERÊNCIAS}

BISHOP, Alan. Enculturación Matemática: la educación matemática desde una perspectiva cultural. Traducción de Genis Sánchez Barberán. Barcelona: Paidós, 1999

BRASIL. Base Nacional Comum Curricular. Brasília: Ministério da Educação, 2017. Disponível em: http://basenacionalcomum.mec.gov.br/wpcontent/uploads/2018/12/BNCC_19dez2018 site.pdf_Acesso em 11 de março de 2019.

BRASIL. Secretaria de Educação Fundamental. Parâmetros curriculares nacionais: matemática / Secretaria de Educação Fundamental. - Brasília: MEC/SEF, 1997. vol. 3.

CELLARD, André. A análise documental. In: A pesquisa qualitativa: enfoques epistemológicos e metodológicos/Tradução de Ana Cristina Nasser. Petrópolis, RJ: Vozes, 2008, p. 295-316.

FRANCO, Maria Amélia do Rosário Santoro. Prática Pedagógica e docência: um olhar a partir da epistemologia do conceito. Rev. Bras. Estud. Pedagog. (on-line), Brasília, v. 97, n. 247, p. 534-551, set./dez. 2016.

GATTI, Bernardete Angelina, BARRETO, Elba Siqueira de Sá e ANDRÉ, Marli Eliza Dalmazo. Políticas docentes no Brasil: um estado da arte / Bernardete Angelina Gatti, Elba Siqueira de Sá Barretto e Marli Eliza Dalmazo de Afonso André. - Brasília: UNESCO, 2011.

GODOY, Elenilton Vieira. Currículo, Cultura e Educação matemática: Uma aproximação Possível. 2011. 201 f. Tese (Doutorado em Educação) - Faculdade de Educação, Universidade de São Paulo, São Paulo, 2011.

GOODSON, Ivor F. Currículo: teoria e história. Petrópolis, RJ: vozes, 2013. 
LOPES, Alice Casimiro; MACEDO, Elizabeth. Teorias do Currículo. São Paulo: Cortez, 2011.

LOPES, Alice Casimiro. Políticas de Currículo: Recontextualização e Hibridismo.

Currículos sem Fronteiras, v.5, n.2, pp. 50-64, jul/dez. 2005. Disponível em http://www.curriculosemfronteiras.org/vol5iss2articles/lopes.pdf. Acesso em 10 de fevereiro de 2021.

\section{LÜDKE, Menga e ANDRÉ, Marli E. D. A. Pesquisa em educação: abordagens qualitativas. São Paulo: EPU, 1986.}

MAINARDES, Jefferson. Abordagem do ciclo de políticas: uma contribuição para a análise de políticas educacionais. Educ. Soc., Campinas, vol. 27, n. 94, p. 47-69, jan./abr. 2006. Disponível em http://www.cedes.unicamp.br.

MORGADO, José Carlos; MARTINS, Fernando Benjamin. Projecto Curricular: Mudança de práticas ou oportunidade perdida? Revista de Estudos Curriculares, 2008, 6(1), p.319.

MORENO, Jean Carlos. História na Base Nacional Comum Curricular: Dèja Vu e novos dilemas no século XXI. História \& Ensino, Londrina, v. 22, n. 1, p. 07-27, jan./jun. 2016

PASSOS, Carmem Lúcia Brancaglion; NACARATO, Adair Mendes. Trajetória e perspectivas para o ensino de Matemática nos anos iniciais. Estudos Avançados, Ensino de Ciências, v.32, n.94, pp119-135, (2018).

PIRES, Célia Maria Carolino. Currículos de Matemática: da organização linear à ideia de rede. São Paulo: FTD, 2000.

PIRES, Célia Maria Carolino; SILVA, Márcio Antônio da. Desenvolvimento Curricular no Brasil: trajetórias e desafios. Quadrante, vol. XX n 2, 2011.

SACRISTÁN, José Gimeno. (Org.). Saberes e incertezas sobre o currículo. Porto Alegre: Penso, 2013.

SACRISTÁN, José Gimeno. O Currículo: uma reflexão sobre a prática. Porto Alegre: Artmed, 2000.

SANTOS, Vinício de Macedo. Uma revisão de artigos de revistas especializadas para identificar características da pesquisa atual em Educação Matemática. São Paulo, 2003. Mimeografado.

YOUNG, Michael. O futuro da educação em uma sociedade do conhecimento: o argumento radical em defesa de um currículo centrado em disciplinas. Revista Brasileira de Educação, v. 16, n. 48 set/dez 2011, p. 609-623. 


\section{Legislação}

Resolução CNE/CP 2/2017. Diário Oficial da União, Brasília, 22 de dezembro de 2017, Seção 1, pp. 41 a 44. 